\title{
Antioxidant Activity of Hypericum androsaemum Infusion: Scavenging Activity against Superoxide Radical, Hydroxyl Radical and Hypochlorous Acid
}

\author{
Patrícia Valentão, ${ }^{a}$ Eduarda Fernandes,${ }^{b}$ Félix Carvalho, ${ }^{b}$ Paula Branquinho Andrade, ${ }^{a}$ \\ Rosa Maria Seabra, ${ }^{a}$ and Maria de Lourdes Bastos $*, b$ \\ ${ }^{a}$ CEQUP/Laboratory of Pharmacognosy, Faculty of Pharmacy, Porto University; ${ }^{b}$ CEQUP/Laboratory of Toxicology, \\ Faculty of Pharmacy, Porto University; R. Aníbal Cunha 164, 4050-047 Porto, Portugal. \\ Received January 7, 2002; accepted June 7, 2002
}

\begin{abstract}
Hypericum androsaemum is a medicinal plant species containing many polyphenolic compounds, namely flavonoids and phenolic acids. Since polyphenolic compounds have high antioxidant potential, the ability of $\boldsymbol{H}$. androsaemum infusion to act as a scavenger of reactive oxygen species (superoxide radical, hydroxyl radical and hypochlorous acid) was investigated. Superoxide radical was generated by the xanthine/xanthine oxidase and phenazine methosulphate/NADH systems. The infusion-mediated prevention of nitroblue tetrazolium reduction by the superoxide radical was used as the measured endpoint. Hydroxyl radical was generated by the $\mathrm{Fe}^{3+}$ EDTA/ascorbate Fenton system, and assayed by evaluating deoxyribose degradation using the thiobarbituric acid method. Hypochlorous acid scavenging activity was tested by measuring the inhibition of hypochlorous acidinduced 5-thio-2-nitrobenzoic acid oxidation to 5,5'-dithiobis(2-nitrobenzoic acid). The tested infusion mainly exhibited a potent scavenging effect on superoxide radicals (although a noncompetitive inhibitory effect on xanthine oxidase was also observed). The infusion also acted as a moderate scavenger of hydroxyl radicals and hypochlorous acid. A phytochemical study of the infusion was also undertaken, and nine phenolic compounds were identified.
\end{abstract}

Key words Hypericum androsaemum; polyphenols; superoxide radical; hydroxyl radical; hypochlorous acid; xanthine oxidase

In the past few years, there has been growing interest in the involvement of reactive oxygen species (ROS) in several pathological situations. ROS produced in vivo include superoxide radical $\left(\mathrm{O}_{2}^{-}\right)$, hydrogen peroxide $\left(\mathrm{H}_{2} \mathrm{O}_{2}\right)$ and hypochlorous acid $(\mathrm{HOCl}) . \mathrm{H}_{2} \mathrm{O}_{2}$ and $\mathrm{O}_{2}^{-}$can interact in the presence of certain transition metal ions to yield a highly-reactive oxidizing species, the hydroxyl radical $\left({ }^{\circ} \mathrm{OH}\right){ }^{1)}{ }^{1}$ The oxidation induced by ROS can result in cell membrane disintegration, membrane protein damage and DNA mutation, which can further initiate or propagate the development of many diseases, such as cancer, liver injury and cardiovascular disease. ${ }^{2)}$ Although the body possesses such defense mechanisms, as enzymes and antioxidant nutrients, which arrest the damaging properties of $\mathrm{ROS}^{3,4)}$ continuous exposure to chemicals and contaminants may lead to an increase in the amount of free radicals in the body beyond its capacity to control them, and cause irreversible oxidative damage." Therefore, antioxidants with free radical scavenging activities may have great relevance in the prevention and therapeutics of diseases in which oxidants or free radicals are implicated. ${ }^{6}$ In this respect, polyphenolic compounds, like flavonoids and phenolic acids, commonly found in plants have been reported to have multiple biological effects, including antioxidant activity. ${ }^{7-10)}$

Leaves of Hypericum androsaemum L. [Guttiferae] are used in folk medicine to prepare teas with diuretic and antihepatotoxic activities. ${ }^{11)}$ So far, studies of this herbal drug involved only the separation and identification of its components, revealing the presence of several flavonoids and phenolic acids; xanthones occur mainly in roots, but minor amounts can also be present in leaves. ${ }^{12-16)}$ These phenolic compounds may be responsible for the properties attributed to this species.

* To whom correspondence should be addressed. e-mail: mlbastos@ff.up.pt
As far as we know, nothing has been reported on the biological properties of this plant. Once this herbal drug began to be used as an infusion, ${ }^{11)}$ the aqueous extract was tested. The chemical composition of an herbal tea can obviously be very complex and may contain several classes of hydrophilic compounds. Since phenolic compounds are known to occur in this species, they will be present in the aqueous extract; since most of them have demonstrated potent antioxidant activities, ${ }^{17)}$ they can confer some of these properties to the infusion. Consequently, it seems important and most realistic to evaluate the activity of the infusion as a whole because interactions may occur among the different compounds present. Therefore, this work reports the effect of the lyophilized infusion on $\mathrm{O}_{2}^{-}$generated by either enzymatic or non-enzymatic systems, as well as the effect on xanthine oxidase activity. The scavenging effects of the lyophilized infusion on OH generated by a Fenton system, in the presence and absence of EDTA or ascorbic acid, and on $\mathrm{HOCl}$ were also evaluated.

\section{MATERIALS AND METHODS}

Standards and Reagents Xanthine, xanthine oxidase (XO) grade I from buttermilk (EC 1.1.3.22), $\beta$-nicotinamide adenine dinucleotide (NADH), phenazine methosulfate (PMS), nitroblue tetrazolium chloride (NBT), ferric chloride anhydrous $\left(\mathrm{FeCl}_{3}\right)$, ethylenediaminetetraacetic acid (EDTA) disodium salt, ascorbic acid, trichloroacetic acid, thiobarbituric acid, deoxyribose, sodium hypochlorite solution with $4 \%$ available chlorine $(\mathrm{NaOCl}), 5,5^{\prime}$-dithiobis(2-nitrobenzoic acid) (DTNB) and sodium borohydride were obtained from Sigma Chemical Co. (St. Louis, U.S.A.). Standards were from Extrasynthese (Genay, France). As 3-O-caffeoylquinic 
acid was not commercially available, it was prepared by transesterification of 5-O-caffeoylquinic acid using tetramethylammonium hydroxide. ${ }^{18,19)}$ All other reagents were of analytical grade. Ultrapure Milli Q water was used throughout.

Plant Infusion Preparation Fifteen grams of $H$. androsaemum dried leaves were extracted with $500 \mathrm{ml}$ of boiling water for $15 \mathrm{~min}$, and filtered over Büchner. The resulting infusion was then lyophilized (Modulyo 4K Freeze Dryer Edwards). The yield of the lyophilized infusion was $0.51 \mathrm{~g}$.

HPLC Analysis of Phenolic Compounds Separation and identification of phenolic compounds was performed as previously reported. ${ }^{13)}$

Evaluation of Superoxide Radical Scavenging Activity Antiradicalar activity was determined spectrophotometrically in a 96-well plate reader (Ceres 900) by monitoring the effect of the lyophilized $H$. androsaemum infusion on the reduction of NBT by superoxide radical at $560 \mathrm{~nm}$.

Non-enzymatic Assay Superoxide radicals were generated by the PMS/NADH system according to a described procedure. ${ }^{2021)}$ The reaction mixtures in the sample wells consisted of NADH $(166 \mu \mathrm{M})$, NBT $(43 \mu \mathrm{M})$, lyophilized infusion $(5.2,10.4,20.8,41.7,83.3,166.7 \mu \mathrm{g} / \mathrm{ml})$ and PMS $(2.7 \mu \mathrm{M})$, in a final volume of $300 \mu \mathrm{l}$. All components were dissolved in phosphate buffer $19 \mathrm{~mm}, \mathrm{pH}$ 7.4. The reaction was conducted at room temperature for $2 \mathrm{~min}$ and initiated by the addition of PMS.

Enzymatic Assay Superoxide radicals were generated by the xanthine/xanthine oxidase $(\mathrm{X} / \mathrm{XO})$ system following a described procedure. ${ }^{20,21)}$ The reaction mixtures in the sample wells consisted of xanthine $(44 \mu \mathrm{M}), \mathrm{XO}(0.29 \mathrm{U} / \mathrm{ml})$, NBT $(50 \mu \mathrm{M})$, and lyophilized infusion $(0.5,1.0,2.1,4.2,8.3$, $16.7 \mu \mathrm{g} / \mathrm{ml})$ in a final volume of $300 \mu \mathrm{l}$. Xanthine was dissolved in $\mathrm{NaOH} 1 \mu \mathrm{M}$, and subsequently in phosphate buffer $50 \mathrm{~mm}$ with EDTA $0.1 \mathrm{~mm}$, pH 7.8 , xanthine oxidase in EDTA $0.1 \mathrm{~mm}$, and the other components in phosphate buffer $50 \mathrm{~mm}$ with EDTA $0.1 \mathrm{~mm}, \mathrm{pH} 7.8$. The reaction was conducted at room temperature for $2 \mathrm{~min}$, and initiated by the addition of XO.

Effect on Xanthine Oxidase Aactivity The effect of the lyophilized infusion on XO activity was evaluated by measuring the formation of uric acid from xanthine in a double beam spectrophotometer (Shimadzu 2600), at room temperature. The reaction mixtures contained the same proportion of components as in the enzymatic assay for superoxide radical scavenging activity, except for NBT, in a final volume of $600 \mu \mathrm{l}$. The absorbance was measured at $295 \mathrm{~nm}$ for $2 \mathrm{~min}$.

Additionally, this procedure was repeated with several concentrations of xanthine $(11,22,44,88 \mu \mathrm{M})$ and $10.7 \mu \mathrm{g} /$ $\mathrm{ml}$ of lyophilized infusion, in order to evaluate the type of XO inhibition.

Hydroxyl Radical Assay The deoxyribose method for determining the scavenging effect of the lyophilized infusion on hydroxyl radicals was performed according to a described procedure. ${ }^{22)}$ Reaction mixtures contained, in a final volume of $1 \mathrm{ml}$, ascorbic acid $(50 \mu \mathrm{M}), \mathrm{FeCl}_{3}(20 \mu \mathrm{M})$, EDTA (2 mM), $\mathrm{H}_{2} \mathrm{O}_{2}(1.42 \mathrm{~mm})$, deoxyribose $(2.8 \mathrm{~mm})$ and lyophilized infusion $(0.03,0.16,0.80,4.00,20.0,100,500 \mu \mathrm{g} / \mathrm{ml})$. All components were dissolved in $\mathrm{KH}_{2} \mathrm{PO}_{4}-\mathrm{KOH}$ buffer $10 \mathrm{~mm}, \mathrm{pH}$ 7.4. After incubation at $37^{\circ} \mathrm{C}$ for $1 \mathrm{~h}, 1 \mathrm{ml}$ of $2.8 \%$ trichloroacetic acid (w/v) and $1 \mathrm{ml}$ of $1 \%$ thiobarbituric acid
(TBA) (w/v) were added, and the mixture was heated in a water bath at $100{ }^{\circ} \mathrm{C}$ for $15 \mathrm{~min}$. The absorbance of the resulting solution was measured at $532 \mathrm{~nm}$. This assay was also performed without ascorbic acid or EDTA.

Hypochlorous Aacid Scavenging Activity Synthesis of Hypochlorous Acid For the assay, $75 \mu \mathrm{M} \mathrm{HOCl}$ was prepared immediately before use by adjusting a solution of $\mathrm{NaOCl}$ to $\mathrm{pH} 6.2$ with diluted sulfuric acid. Its concentration was determined spectrophotometrically at $235 \mathrm{~nm}$ using the molar absorption coefficient of $100 \mathrm{M}^{-1} \mathrm{~cm}^{-1}$. 22)

Synthesis of 5-Thio-2-nitrobenzoic Acid [TNB] TNB was prepared according to a described procedure. ${ }^{23)}$ Briefly, to a $1 \mathrm{~mm}$ solution of DTNB in $50 \mathrm{~mm}$ potassium phosphate buffer ( $\mathrm{pH}$ 6.6), containing $5 \mathrm{~mm}$ EDTA, $20 \mathrm{~mm}$ sodium borohydride was added. The solution was incubated at $37^{\circ} \mathrm{C}$ for $30 \mathrm{~min}$. The concentration of TNB was determined by measuring the absorbance at $412 \mathrm{~nm}$ using the molar absorption coefficient of $13600 \mathrm{M}^{-1} \mathrm{~cm}^{-1}$.

Hypochlorous Acid Sscavenging Assay The assay was performed at room temperature in a cuvette containing a $40 \mu \mathrm{M}$ TNB solution, with or without the lyophilized infusion $(0,62.5,125,250,500,1000 \mu \mathrm{g} / \mathrm{ml})$. The absorbance was measured at $412 \mathrm{~nm}$ before and $5 \mathrm{~min}$ after the addition of hypochlorous acid $(40 \mu \mathrm{M})$.

\section{RESULTS AND DISCUSSION}

The $H$. androsaemum lyophilized infusion strongly scavenged the superoxide radical generated by the enzymatic system in a concentration dependent manner $\left(\mathrm{IC}_{50}=2.9 \mu \mathrm{g} / \mathrm{ml}\right)$, as shown in Fig. 1A. Since an inhibitory effect on the enzyme itself would also lead to a decrease in NBT reduction, ${ }^{3}$ ) the effect of the infusion on the XO activity was checked. In this regard we evaluated the effect of the lyophilized infusion on the metabolic conversion of xanthine to uric acid (Fig. 1A). The results demonstrate that the infusion has a weak inhibitory effect on $\mathrm{XO}$, with an $\mathrm{IC}_{25}$ of $10.7 \mu \mathrm{g} / \mathrm{ml}$. Taking this fact into account, it was not possible to show a clear-cut scavenging effect on superoxide radicals. In view of clarification, we also determined the effect of the infusion on superoxide radicals generated by a non-enzymatic system (Fig. $1 \mathrm{~B})$, which indicated an $\mathrm{IC}_{50}$ of $25.6 \mu \mathrm{g} / \mathrm{ml}$. In order to evaluate the type of XO inhibition of the lyophilized infusion, its activity was tested at different xanthine concentrations [Fig. $2]$. In the presence of the infusion both $V_{\max }$ and $K_{\mathrm{m}}$ lowered, from 7.6 to $4.0 \mu \mathrm{M} / \mathrm{min}$ and from 18.2 to 8.2 (Fig. 2), respectively, suggesting a mixed non-competitive inhibitory effect, that is, the constituents of the infusion bind both to the enzyme and to the $\mathrm{X} / \mathrm{XO}$ complex, but with greater affinity for the latter. ${ }^{24)}$

The $H$. androsaemum lyophilized infusion also appeared to be a scavenger of hydroxyl radical generated by a Fenton system in a concentration dependent manner (Table 1). However, some compounds are capable of redox cycling the metal ion required for hydroxyl generation, thus increasing the radical production, exhibiting a pro-oxidant activity. ${ }^{25)}$ In order to evaluate the pro-oxidant potential of the infusion, we modified the method by omitting ascorbic acid. Indeed, we found that the $H$. androsaemum lyophilized infusion was a very effective substitute for ascorbic acid when the concentration was higher than $4.00 \mu \mathrm{g} / \mathrm{ml}$ (Table 1). Thus, for concentra- 

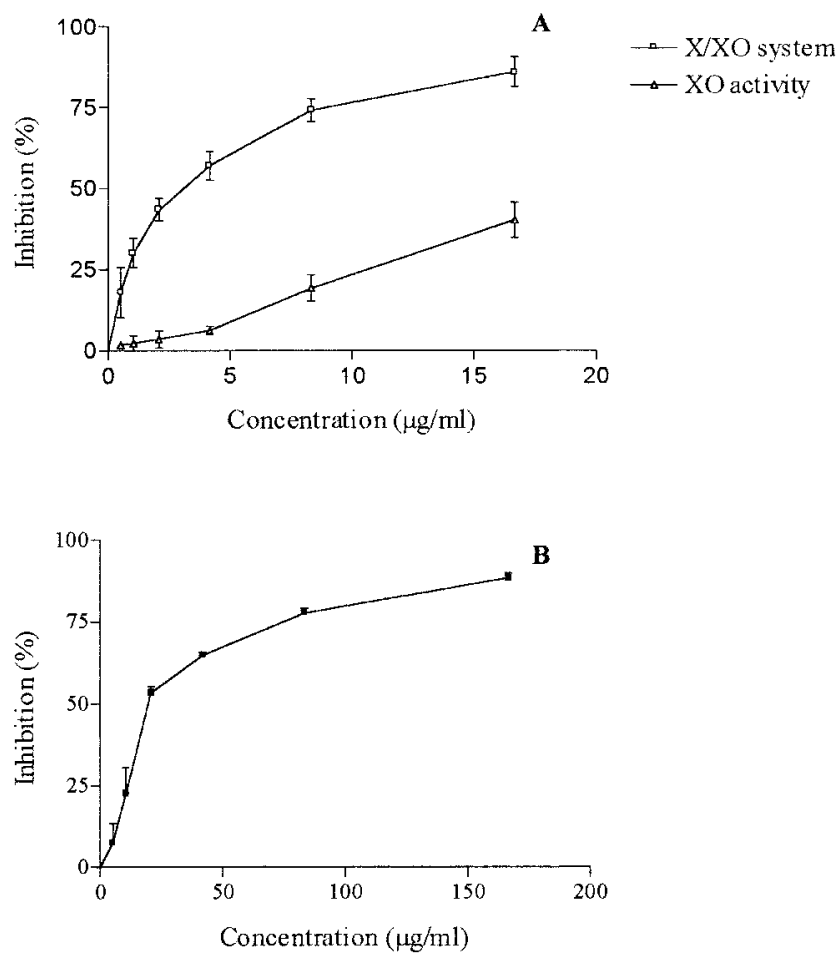

Fig. 1. Effect of H. androsaemum Lyophilized Infusion on (A) NBT Reduction Induced by Superoxide Radical Generated in a X/XO System and XO Activity and (B) NBT Reduction Induced by Superoxide Radical Generated in a NADH/PMS System

Values show the mean \pm S.E. from 4 experiments performed in triplicate.

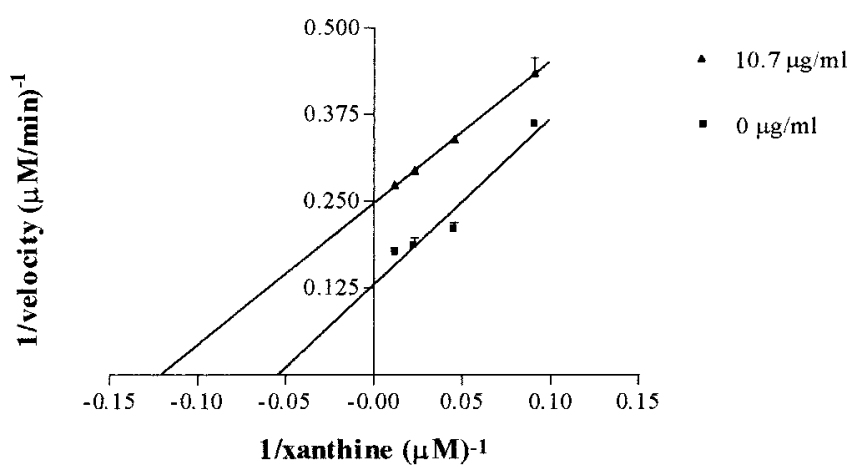

Fig. 2. Lineweaver-Burk Plots for the Inhibition of XO by H. androsaemum Lyophilized Infusion with Xanthine as a Substrate

Values show the mean \pm S.E. from 3 experiments performed in triplicate.

Table 1. Absorbances and Scavenging Effect Obtained in the Deoxyribose Assay in the Presence and Absence of Ascorbic Acid (-AA) or EDTA (-EDTA)

\begin{tabular}{ccccc}
\hline \hline $\begin{array}{c}\text { Concentration of } \\
\begin{array}{c}\text { H. androsaemum } \\
\text { extract }(\mu \mathrm{g} / \mathrm{ml})\end{array}\end{array}$ & ABS & $\begin{array}{c}\text { Scavenging } \\
\text { ratio (\%) }\end{array}$ & ABS (-AA) & ABS (-EDTA) \\
\hline 0.00 & 0.374 & - & 0.158 & 0.250 \\
0.03 & 0.358 & 4.1 & 0.136 & 0.240 \\
0.16 & 0.345 & 7.8 & 0.137 & 0.224 \\
0.80 & 0.303 & 19.0 & 0.125 & 0.223 \\
4.00 & 0.267 & 28.6 & 0.149 & 0.229 \\
20.00 & 0.288 & 23.2 & 0.237 & 0.226 \\
100.00 & - & - & 0.364 & 0.172 \\
500.00 & - & - & 0.396 & 0.115 \\
\hline
\end{tabular}

tions above $4.00 \mu \mathrm{g} / \mathrm{ml}, H$. androsaemum lyophilized infusion may act as a pro-oxidant. The assay performed in the absence of EDTA is also useful because it provides an indication of the potential of the infusion to chelate iron ions. $\mathrm{Fe}^{3+}$ chelators will decrease the amount of thiobarbituric-reactive substances formed from deoxyribose as a result of $\mathrm{Fe}^{3+}$ removal from the sugar. ${ }^{26)}$ Notably, the lyophilized infusion was able to chelate iron ions, as this effect was observed in the absence of EDTA (Table 1).

Hypochlorous acid is a strong ROS produced in organisms by oxidation of $\mathrm{Cl}^{-}$ions at sites of inflammation by the neutrophil enzyme myeloperoxidase. ${ }^{1)}$ The oxidizing properties of $\mathrm{HOCl}$ induce the conversion of TNB $\left(\lambda_{\max }=412 \mathrm{~nm}\right)$ to $\operatorname{DTNB}\left(\lambda_{\max }=325 \mathrm{~nm}\right){ }^{27)} \mathrm{A} \mathrm{HOCl}$ scavenger inhibits the oxidation of TNB by this species. When the antioxidant protection against damage by $\mathrm{HOCl}$ was evaluated, the $H$. androsaemum lyophilized infusion exhibited protective activity, as shown in Fig. 3A.

In order to correlate the observed antioxidant activity with the phenolic composition of $H$. androsaemum infusion, an aliquot of the lyophilized infusion was subjected to HPLCDAD analysis. The results obtained revealed a phenolic fingerprint composed of nine identified compounds, namely 3and 5-O-caffeoylquinic acids, quercetin 3-sulphate, quercetin 3 -galactoside, quercetin 3-glucoside, quercetin 3-arabinoside and quercetin.

The antioxidant activity of 5-O-caffeoylquinic acid has already been observed in several experimental models and for

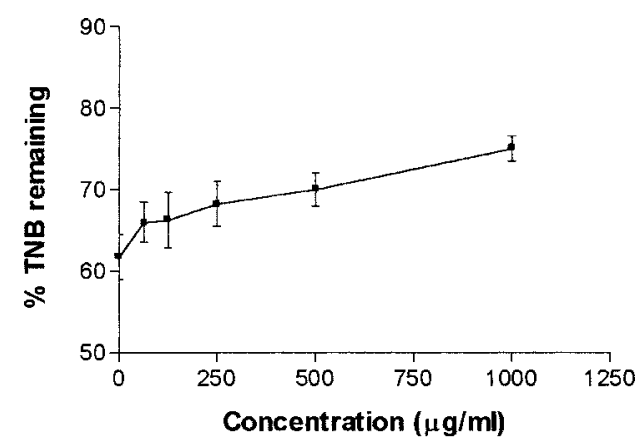

Fig. 3. Effect of H. androsaemum Lyophilized Infusion on the Oxidation of TNB by $\mathrm{HOCl}$

The amount of TNB unchanged after incubation is calculated and expressed as the percentage of the initial value. Values show the mean \pm S.E. from 4 experiments performed in duplicate.

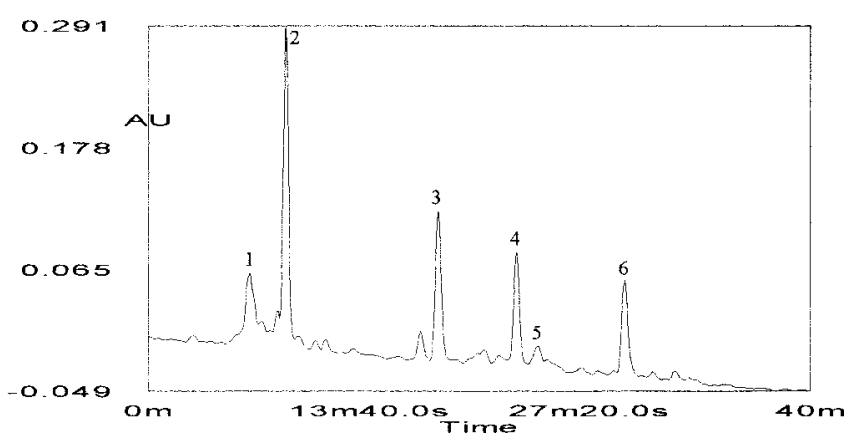

Fig. 4. HPLC Phenolic Profile of H. androsaemum

Detection at $350 \mathrm{~nm}$. Peaks: (1) 3-O-caffeoylquinic acid; (2) 5-O-caffeoylquinic acid; (3) quercetin 3-sulphate; (4) quercetin 3-galactoside+quercetin 3-glucoside; (5) quercetin 3-arabinoside; (6) quercetin. 
different ROS, such as the in vitro lipoprotein oxidation model, ${ }^{10)}$ alkylperoxyl radical scavenging activity in a bioassay based on the bactericidal effect of this radical, ${ }^{28)}$ scavenging activity on superoxide radicals enzymatically generated, ${ }^{29)}$ a free radical method using 2,2-diphenyl-1-picrylhydrazyl (DPPH') and an oxidation system using a linoleic acid emulsion whose endpoint is malonaldehyde. ${ }^{30)}$ The antioxidant capacity of quercetin and its derivatives has also been previously reported in different assays, such as in the prevention of methyl linoleate hydroperoxide formation, ${ }^{31)}$ the scavenging of superoxide radical generated either by an enzymatic system or non-enzymatically, ${ }^{32)}$ the inhibition of 5lipoxygenase and cycloxygenase activities in rat peritoneal leukocytes, and the inhibition of lipid peroxidation in rat liver microsomes. ${ }^{33)}$

Besides these protective effect evaluations, some pharmacokinetic studies with these compounds have already been developed. The gastrointestinal bioavailability of some dietary flavonoids was evaluated in human volunteers, both in the free aglycone and glycoside form, as compounds detected in blood and urine in the non-esterified form. ${ }^{34-36)}$ These studies have also demonstrated that glycosilated flavonols, the predominant form in plants, are bioavailable in the gastrointestinal tract to a larger extent than other forms. In the onion, $52 \%$ of the flavonol glycosides were absorbed in human, whereas only $24 \%$ and $17 \%$ of quercetin and rutin were absorbed. ${ }^{35)}$ The type of originated flavonoid metabolites depends on the hydroxylation pattern, with compounds having 5,7- and 3',4'-hydroxylation being susceptible to hydrolysis and heterocyclic ring cleavage by microbiological degradation in the colon. ${ }^{34,36)}$

In conclusion, regarding the predominance of several quercetin glycosides in the lyophilized infusion of $H$. androsaemum, the scavenging activities observed against superoxide radical, hydroxyl radical and hypochlorous acid may be due, most probably, to the presence of these compounds, which contribute to the protective effects observed in this study.

Acknowledgments The authors are grateful to the Agência Inovação and PRAXIS XXI [PLANTAMEDI project] for financial support of this work. P. Valentão is indebted to Fundação para a Ciência e a Tecnologia for a $\mathrm{PhD}$ grant [PRAXIS XXI/BD/15740/98].

\section{REFERENCES}

1) Aruoma O. I., Halliwell B., Hoey B. M., Butler J., Free Rad. Biol. Med., 6, 593-597 (1989).

2) Liao K.-L., Yin M.-C., J. Agric. Food Chem., 48, 2266-2270 (2000).

3) Halliwell B., Aeschbach R., Löliger J., Aruoma O. I., Food Chem. Toxicol., 33, 601-617 (1995).

4) Sies H., Eur. J. Biochem., 215, 213-219 (1993).
5) Tseng T.-H., Kao E.-S., Chu C.-Y., Chou F.-P., Lin Wu H.-W., Wang C.-J., Food Chem. Toxicol., 35, 1159-1164 (1997).

6) Soares J. R., Dinis T. C. P., Cunha A. P., Almeida L. M., Free Rad. Res., 26, 469-478 (1997).

7) Brown J. E., Rice-Evans C. A., Free Rad. Res., 29, 247-255 (1998).

8) Gil M. I., Ferreres F., Tomás-Barberán F. A., J. Agric. Food Chem., 47, 2213-2217 (1999).

9) Kähkönen M. P., Hopia A. I., Vuorela H. J., Rauha J.-P., Pihlaja K., Kujala T. S., Heinonen M., J. Agric. Food Chem., 47, 3954-3962 (1999).

10) Vinson J. A., Dabbagh Y. A., Serry M. M., Jang J., J. Agric. Food Chem., 43, 2800-2802 (1995).

11) Costa A. F., "Farmacognosia," Vol. II, Fundação Calouste Gulbenkian, Lisbon, 1994, pp. 1022-1023.

12) Andrade P. B., Seabra R. M., Valentão P., Areias F., J. Liq. Chrom. Rel. Technol., 21, 2813-2820 (1998).

13) Dias A. C. P., Seabra R. M., Andrade P. B., Fernandes-Ferreira M., J. Liq. Chrom. Rel. Technol., 22, 215-227 (1999).

14) Seabra R. M., Correia Alves A., Planta Med., 55, 404 (1989).

15) Seabra R. M., Correia Alves A., Fitoterapia, 61, 146-147 (1990).

16) Schmidt W., Abd El-Mawla A. M. A., Wolfender J.-L., Hostettmann K., Beerhues L., Planta Med., 66, 380-381 (2000).

17) Yoshino K., Hara Y., Sano M., Tomita I., Biol. Pharm. Bull., 17, $146-$ 149 (1994).

18) Clifford M. N., Kellard B., Birch G. G., Food Chem., 33, 115-123 (1989).

19) Clifford M. N., Kellard B., Birch G. G., Food Chem., 34, 81-88 (1989).

20) Fernandes E., Borges F., Milhazes N., Carvalho F. D., Bastos M. L., Toxicol. Lett., 109, 42 (1999).

21) Valentão P., Fernandes E., Carvalho F., Andrade P. B., Seabra R. M., Bastos M. L., J. Agric. Food Chem., 49, 3476-3479 (2001).

22) Payá M., Halliwell B., Hoult J. R. S., Biochem. Pharmacol., 44, $205-$ 214 (1992).

23) Ching T.-L., De Jong J., Bast A., Anal. Biochem., 218, 377-381 (1994).

24) Moran L. A., Scrimgeour K. G., Horton H. R., Ochs R. S., Rawn J. D., "Biochemistry," Neil Patterson Publishers/Prentice-Hall, Inc., New Jersey, 1994.

25) Li C., Xie B., J. Agric. Food Chem., 48, 6362-6366 (2000).

26) Moran J. F., Klucas R. V., Grayer R. J., Abian J., Becana M., Free Rad. Biol. Med., 22, 861-870 (1997).

27) Künzel J. K. v. F. D., v. d. Zee J., Ijzerman A. P., Drug Develop. Res., 37, 48-54 (1996).

28) Sawa T., Nakao M., Akaike T., Ono K., Maeda H., J. Agric. Food Chem., 47, 397-402 (1999).

29) Nakatani N., Kayano S., Kikuzaki H., Sumino K., Katagiri K., Mitani T., J. Agric. Food Chem., 48, 5512-5516 (2000).

30) Fukumoto L. R., Mazza G., J. Agric. Food Chem., 48, 3597-3604 (2000).

31) Hopia A., Heinonen M., J. Am. Oil Chem. Soc., 76, 139-144 (1999).

32) Robak J., Gryglewski R. J., Biochem. Pharmacol., 37, 837-841 (1988).

33) Laughton M. J., Evans P. J., Moroney M. A., Hoult J. R. S., Halliwell B., Biochem. Pharmacol., 42, 1673-1681 (1991).

34) Croft K. D., Ann. N.Y. Acad. Sci., 854, 435-442 (1998).

35) Day A. J., Williamson G., "Plant Polyphenols 2: Chemistry, Biology, Pharmacology, Ecology," Kluwer Academic, Plenum Publishers, New York, 1999, pp. 415-434.

36) Hollman P. C. H., van Trijp J. M. P., Buysman M. N. C. P., Gaag M. S. v. d., Mengelers M. J. B., de Vries J. H. M., Katan M. B., FEBS Lett., 418, 152-156 (1997) 